\title{
Sodium polyphosphate and polyethylenimine enhance the antimicrobial activities of plant essential oils
}

\author{
Heidi A. Wright and Byron F. Brehm-Stecher* \\ Rapid Microbial Detection and Control Laboratory, Department of Food Science and Human Nutrition, \\ lowa State University, Ames, IA, USA \\ *Corresponding author's e-mail address: byron@iastate.edu
}

Published online: 29 December 2016 (version 1)

Cite as: Wright, H.A., Brehm-Stecher, B.F. ScienceOpen Research 2017 (DOI: 10.14293/S2199-1006.1.SOR-LIFE.Z72TPO.v1)

Reviewing status: Please note that this article is under continuous review. For the current reviewing status and the latest referee's comments please click here or scan the QR code at the end of this article.

Primary discipline: Microbiology \& Virology

Associated disciplines: General Agriculture

Keywords: Natural antimicrobials, antimicrobial enhancement, chelators, foodborne pathogens

\begin{abstract}
Plant extracts have been used for millennia for treatment of disease, with much recent interest focusing on the antimicrobial activities of plant essential oils (EOs). Although EOs are active against common microbial pathogens, their effective use as topical, environmental, or food antimicrobials will require EO-based formulations with enhanced antimicrobial activities. In this study, two polyionic compounds, sodium polyphosphate (polyP, a polyanion) and polyethylenimine (PEI, a polycation), were evaluated for their abilities to enhance the antimicrobial activities of six EOs against the human pathogens Escherichia coli 0157:H7, Salmonella enterica subsp. enterica ser. Minnesota, Pseudomonas aeruginosa, Listeria monocytogenes, Staphylococcus aureus, and Candida albicans. EOs tested were cinnamon, clove, regular and redistilled oregano, and two types of thyme oil. EOs were examined via disk diffusion and broth microdilution, either alone or in the presence of subinhibitory levels of polyP or PEI. Both polyP and PEI were found to be effective enhancers of EO activity against all strains examined, and calculation of fractional inhibitory indices for select EO/organism pairings demonstrated that true synergy was possible with this enhancement approach. Experiments with a deep-rough strain of $S$. Minnesota probed the role of the outer membrane in both intrinsic resistance to EOs and enhancement by polyions. The use of polyP and PEI for boosting the antimicrobial activities of EOs may eventually facilitate the development of more effective EO-based antimicrobial treatments for use in applications such as wound treatment, surface disinfection, or as generally recognized as safe antimicrobials for use in foods or on food contact surfaces.
\end{abstract}

\section{INTRODUCTION}

There is substantial consumer demand for and industrial interest in development of "natural" antimicrobials for use in disinfection and cleaning of food contact surfaces, for treatment of foods themselves (food-grade antimicrobial fruit or vegetable washes, for example), or for use as topical antimicrobials, as alternatives to antibiotics. Plant essential oils (EOs) are a promising botanical source for such natural antimicrobials. The term "essential oil" is a collective descriptor for the fragrant, oily liquids obtained from the leaves, flowers, bark, bulbs, roots, or other plant components through extraction methods such as steam distillation, physical expression, supercritical fluid extraction, or enfleurage (extraction into solid, odorless fat) [1-4]. EOs have long standing in human culture as flavorant and aroma compounds and have also been valued for their pharmacological properties as analgesics/local anesthetics, or for their anti-inflammatory or spasmolytic properties [1,2]. Although formal development of EOs as antibacterials began in the late 19th century [2], their widespread use in this application was likely eclipsed by the ready availability of synthetic antimicrobials such as dyes, and later in the next century, by the discovery of antibiotics. Today, factors such as the widespread development of resistance to antibiotics and increasing consumer demands for "natural" or "green" alternatives to traditional food preservatives or disinfectants have driven a renewed interest in the use of EOs as antimicrobials. Advantages of EOs include the fact that many have generally recognized as safe (GRAS) status and are already used widely in foods, cosmetics, or in personal care products as flavorants, aroma compounds, or functional ingredients [2,4]. A key drawback is that although some EOs have relatively wide antimicrobial spectra [4], they typically demonstrate high minimum inhibitory concentrations (MICs) when added to complex systems. For example, in foods, the amount of EO needed to inhibit pathogens may be as much as 100 -fold greater than the amount needed to inhibit the same pathogens in microbiological media [2]. Given the intense flavor and aroma 
profiles of most EOs, such high levels may be organoleptically unacceptable, limiting the use of these antimicrobials in foodrelated applications [4-6]. In topical applications, the use of certain concentrated EOs or EO-containing products has been linked to contact dermatitis and even gynecomastia in prepubescent boys $[7,8]$. Therefore, methods for enhancing the antimicrobial activities of EOs may enable the practical use of these otherwise promising natural compounds in food, environmental, or topical medical applications by achieving equivalent (or better) antimicrobial efficacy, but at lower EO concentrations $[4,6]$.

A critical factor affecting the efficacy of hydrophobic compounds (or mixtures of hydrophobic compounds, such as found in EOs) against gram-negative bacteria is the permeability barrier posed by the outer membrane (OM) [9]. The hydrophilic, quasicrystalline "tiled roof" surface of the intact OM effectively limits the entry of hydrophobic EO components into the cell $[9,10]$. A number of strategies have been devised to address the permeability barrier posed by the OM, with an aim toward improving the efficacy of antibiotics [6,9-12], biocides [13], or individual EO components such as thymol and carvacrol [6] against gram-negative bacteria. Typically, these strategies involve co-treatment of target bacteria with polycationic or polyanionic molecules including polyphosphates [14], polyethylenimine (PEI) [10-13], or metal chelators such as ethylenediaminetetraacetic acid (EDTA) $[6,11,13,15]$ and organic acids [5,6]. In these applications, polyphosphates, EDTA, and organic acids are thought to disrupt the integrity of the OM by chelating the divalent cations involved in electrostatic linkage, or "bridging", of adjacent LPS molecules [6,11,13,15,16], and polycationic molecules such as PEI and chitosan are thought to interact with Lipopolysaccharide (LPS, itself an anion) in the OM to introduce disorder in LPS-LPS interactions, interfering with the OM's barrier function [9-12]. An excellent review of the diversity of (mostly cationic) molecules known to be capable of permeabilizing the gram-negative OM is provided by Vaara [9]. Although much work has focused on using polyionic compounds for enhancing antimicrobial activity against gram-negative bacteria, little is known about how these compounds may affect uptake of antimicrobials by other cell types, such as gram-positive bacteria or yeasts. In approaching this study, we reasoned that because polyionic permeabilizers such as polyP and PEI have been previously shown to facilitate the uptake of hydrophobic antibiotics by gram-negative bacteria, they may also serve as effective co-incubants for promoting the uptake of other hydrophobic compounds or mixtures, namely EOs. Therefore, we sought to characterize the efficacy of polyP and PEI as promoters of EO uptake in gram-negative bacteria using six commonly available EOs. Once we established that polyP and PEI were capable of enhancing EO activity against select gram-negative bacteria (Escherichia coli 0157:H7, Salmonella enterica subsp. enterica ser. Minnesota, Pseudomonas aeruginosa), we sought to extend these effects to other cell types, including gram-positive bacteria (Listeria monocytogenes,
Staphylococcus aureus) and a pathogenic yeast (Candida albicans). The role of the $\mathrm{OM}$ in susceptibility of gram-negative bacteria to EOs and to EO/polyion combinations was also examined using a "deep-rough" mutant of $S$. Minnesota. Finally, we sought to characterize whether the EO-enhancing activities of polyP and PEI were truly synergistic, versus simply additive, by measuring fractional inhibitory concentrations (FICs) and calculating FIC indices for select pathogen-oil pairings.

\section{MATERIALS AND METHODS \\ Chemicals and essential oils}

BEKAPLUS FS, a food grade sodium polyphosphate (polyP) salt, was from BK Giulini, (Simi Valley, CA). Stock solutions of polyP (5\% w/v, final $\mathrm{pH}$ of 6.8$)$ were prepared in sterile water and used the same day. Polyethylenimine (PEI; branched, avg. MW 25,000) was from Sigma-Aldrich (St. Louis, MO). Stock solutions of PEI ( $2.5 \mathrm{mg} / \mathrm{ml}$, final $\mathrm{pH}$ of $\sim 9.2$ ) were prepared in sterile water. The following EOs were sourced from Van Beek Natural Science (Orange City, IA): cinnamon, clove, oregano, redistilled oregano, spike thyme, and white thyme. According to certificates of analysis provided by the vendor, the oils contained the following levels of active compounds: cinnamon oil, $70.42 \%$ cinnamaldehyde; clove oil, $87.6 \%$ eugenol; oregano oil, $67.4 \%$ carvacrol, $3.8 \%$ thymol; redistilled oregano oil, 96.4\% carvacrol, $2.7 \%$ thymol; spike thyme oil, $71.01 \%$ carvacrol; white thyme oil, $50.19 \%$ thymol. Neat oils were added directly to growth media and mixed thoroughly prior to use.

\section{Microbial strains and culture conditions}

E. coli 0157:H7 ATCC 35150, S. enterica subsp. enterica ser. Minnesota SLH154 (wild-type clinical isolate, Wisconsin State Lab of Hygiene), S. Minnesota R613 (Re chemotype "deeprough" mutant, Salmonella Genetic Stock Centre, Calgary, Alberta, CA), P. aeruginosa ATCC 27853, S. aureus ATCC 29523, and L. monocytogenes $\mathrm{F} 6854$ were grown at $30^{\circ} \mathrm{C}$ in cation-adjusted Mueller Hinton broth (CAMHB) (Becton Dickinson and Company, Franklin Lakes, NJ) as described in the Clinical and Laboratory Standards Institute (CLSI) document M7-A7 [17]. C. albicans ATCC 90028 was grown at $35^{\circ} \mathrm{C}$ in RPMI 1640 broth (Sigma-Aldrich) as described in CLSI document M27-A2 [18].

\section{Disk diffusion}

The baseline antimicrobial activities of the six EOs were determined using a standard disk diffusion assay, as described in CLSI document M2-A9 [19]. For evaluation of EO activity in the presence of polyionic enhancers, an agar overlay-based modification of this assay was used, with enhancers and test inocula commingled in the overlay [20]. Briefly, cells were grown in CAMHB for $24 \mathrm{~h}$ at $30^{\circ} \mathrm{C}$ and diluted to a working concentration of $\sim 10^{7} \mathrm{CFU} / \mathrm{ml}$ in phosphate buffered saline. An aliquot of this cell suspension was added to a Mueller 
Hinton agar overlay $\left(0.7 \%\right.$ agar) tempered to $50^{\circ} \mathrm{C}$, yielding a final inoculum of $\sim 10^{6} \mathrm{CFU} / \mathrm{ml}$. This seeded overlay mixture was immediately poured over gelled Mueller Hinton agar (1.5\% agar) in small petri dishes $(60 \mathrm{~mm}$ diam., with the exception of the $100 \mathrm{~mm}$ diameter plate shown in Figure 7) and left to solidify. For treatments containing polyP or PEI, aliquots of polyion working stocks were added to the tempered overlays before pouring to yield final enhancer concentrations of $1 \%$ (polyP) or $50 \mu \mathrm{g} / \mathrm{ml}$ (PEI). Sterile paper disks (BBL, Becton Dickson and Company, Franklin Lakes, NJ) were saturated with $15 \mu \mathrm{l}$ portions of each EO to be tested and placed aseptically on the gelled agar overlays, and plates were incubated at $30^{\circ} \mathrm{C}$ for $24 \mathrm{~h}$. Zones of inhibition (ZOI, diameter reported in $\mathrm{mm}$ ) were measured from the bottom of each plate after incubation. Within each experiment, all treatments were performed in duplicate, and all experiments were performed in triplicate. Zones reported represent the averages of these replicate measurements. Statistical analysis was performed using SAS software (v 9.1, SAS Institute Inc., Cary, NC). Statistical significance in ZOI size between treatments was tested using Tukey's test for multiple comparisons $(p<0.05)$.

\section{Minimum inhibitory concentration}

To obtain MICs for subsequent calculation of FICs, the antimicrobial activities of two EOs (cinnamon and redistilled oregano oils) were tested via broth microdilution assay against a representative gram-negative bacterium (E. coli 0157:H7), a gram-positive bacterium ( $L$. monocytogenes), and a yeast (C. albicans) using a Bioscreen $\mathrm{C}$ microbial growth analyzer (Labsystems, Helsinki, Finland). Briefly, stock solutions of EOs were prepared by direct addition of oils to CAMHB, with thorough vortexing to ensure adequate mixing. Serial twofold dilutions of EO-containing CAMHB were made into plain CAMHB as described previously [21], yielding a series of wells containing EO levels ranging from $1 \%$ to $0.0039 \%$ EO (v/v). Fresh CAMBH was added to bring the final volume of all wells to $200 \mu \mathrm{l}$, and controls (growth media without added EOs) were included in every experiment. For MIC determinations of bacteria in the presence of polyionic enhancers, appropriate aliquots of polyP or PEI stocks were added prior to bringing wells up to volume with fresh $\mathrm{CAMBH}$, yielding final concentrations of polyP and PEI of $1 \%$ and $50 \mu \mathrm{g} / \mathrm{ml}$, respectively. Final $\mathrm{pH}$ values for CAMBH to which polyP or PEI had been added ranged between 7.1 and 7.3 (close to the manufacturer's specifications of $7.3 \pm 0.1$ ). Preliminary work demonstrated that $C$. albicans was inhibited by $1 \%$ polyP alone. Therefore, a subinhibitory level of $0.25 \%$ was used to determine the MICs of EO/enhancer combinations for this organism. Additionally, in this liquid system, PEI was found to be inhibitory to C. albicans at all levels tested, precluding testing of PEI-mediated MIC reduction for this organism. For MIC determinations (and also for FIC determinations, below) all treatments within each experiment, and all experiments, were performed in triplicate.
Microbial cells were cultured and further diluted in fresh media, then added to a final concentration of $10^{5}$ cells per well. Plates were incubated in the Bioscreen for $24 \mathrm{~h}$ at $30^{\circ} \mathrm{C}$ $\left(35^{\circ} \mathrm{C}\right.$ for C. albicans) and the instrument was programmed to measure optical density at $600 \mathrm{~nm}$ every $15 \mathrm{~min}$, with shaking for $30 \mathrm{~s}$ prior to each reading to ensure adequate suspension of cells. The MIC was defined as the lowest EO concentration that completely inhibited microbial growth (OD increase $\leq 0.05$ ) after $24 \mathrm{~h}$ incubation [22].

\section{Fractional inhibitory concentration}

For assays involving combinations of EOs and polyionic enhancers, FICs were determined as a means to detect and quantify formal synergy between these components, versus simple additive effects. To do this, MICs for EOs and polyionic enhancers were determined both individually and in combination, using the methods for MIC determination described above, and FIC indices were calculated according to the method of Pankey and Ashkraft [23], using the following formulas:

FIC $($ Essential oil $)=($ MIC combination/MIC oil alone $)$

FIC $($ Polyion $)=($ MIC combination $/$ MIC polyion alone $)$

$\sum$ FIC $=$ FIC (Essential oil) + FIC (Polyion)

Interactions with $\sum$ FIC $\leq 0.5$ were classified as "synergistic," those with $\sum$ FIC $\geq 4.0$ were classified as "antagonistic," and interactions having $\sum$ FIC between 0.5 and 4.0 were classified as "indifferent" [23]. Because E. coli and L. monocytogenes were not inhibited by polyP alone, even at very high concentrations, the highest level of polyP tested (10\%) was used to calculate FIC values for these organisms.

\section{Results \\ Disk diffusion}

All EOs were inhibitory alone to the organisms tested, producing modest ZOIs of 10-17 mm for L. monocytogenes, 9-20 mm for $P$. aeruginosa, 14-26 $\mathrm{mm}$ for wild-type $S$. Minnesota, and 15-25 $\mathrm{mm}$ for $E$. coli. Of all wild-type strains, the largest ZOIs for oils alone were measured for $S$. aureus, with ZOIs of 18-40 mm. However, the "deep-rough" (Re chemotype) $S$. Minnesota was the most intrinsically susceptible organism to EOs alone, with ZOIs of 26-45 mm, roughly twice the size as those measured for wild-type ("smooth") S. Minnesota. (Figures 1-6). For all organisms tested, clove was the least active EO. Combination of EOs with subinhibitory concentrations of polyP $(1 \%)$ or PEI $(50 \mu \mathrm{g} / \mathrm{ml})$ significantly $(p<0.05)$ increased zone sizes for all bacteria tested, indicating at least an additive effect for these enhancers. Exceptions include the nonsignificant increases in ZOI seen for the PEI/clove combination with $P$. aeruginosa, wild-type $S$. Minnesota and $S$. aureus, or the $\mathrm{PEI} /$ cinnamon combination with wild-type $S$. Minnesota (Figures 2, 3, and 5).

Remarkably, we found that co-application of polyP or PEI further enhanced the activities of EOs against the intrinsically 
susceptible "deep-rough" $S$. Minnesota strain. Table 1 summarizes the increases in ZOIs seen for polyP or PEI for the six bacteria tested. These data are reported as the range of ZOI increase (in $\mathrm{mm}$ ) seen across all pathogen/polyion/EO pairings. For gram-negative bacteria, the smallest overall increases were noted for $P$. aeruginosa and wild-type $S$. Minnesota treated with PEI. The activities of EOs against $S$. aureus, the most intrinsically susceptible wild-type organism, were also only minimally enhanced by either polyion. These data highlight that although the activities of all EOs could be enhanced by polyP and PEI, the degree of enhancement varied according to the pathogen/polyion/EO pairing tested.

Although PEI was inhibitory to $C$. albicans at all concentrations used in liquid media (see section Minimum inhibitory concentration), we were able to titrate the level of PEI to a subinhibitory, yet EO-enhancing level of $5 \mu \mathrm{g} / \mathrm{ml}$ when incorporated into the agar overlays used in disk diffusion experiments. Treatment of $C$. albicans with either $1 \%$ polyP or $5 \mu \mathrm{g} / \mathrm{ml}$ PEI led to larger ZOIs for all oils. However, ZOIs for both EO-only controls and polyion-treated $C$. albicans were not always measurable, as their edges were often diffuse, without a clear line of demarcation. An exception to this observation was found with cinnamon oil, which did yield crisp, measurable zones with either the oil alone or the oil combined with $0.25 \%$ polyP or $5 \mu \mathrm{g} / \mathrm{ml}$ PEI (Figure 7).

Apart from leading to increases in zone size for the various oils used, we observed that treatment of $P$. aeruginosa with $1 \%$ polyP also caused the bacterial lawn to change in color from a greenish-blue hue to a white or cream color (data not shown). This color change did not occur in lawns treated with PEI. The potential significance of this observation is discussed below.

\section{Minimum inhibitory concentration}

A broth microdilution assay was used to determine the MICs of EOs alone and in the presence of polyionic enhancers. MIC values of the enhancers alone were also determined for use in calculating FIC indices for EO/polyion combinations. Cinnamon and redistilled oregano oils were chosen as representative oils for MIC and FIC determination on the basis of their disk diffusion activities and on their chemical compositions, with cinnamaldehyde and carvacrol being the main constituents for cinnamon and oregano oils, respectively (see "Materials and Methods"). MIC results paralleled those obtained for disk diffusion, with L. monocytogenes showing a higher intrinsic

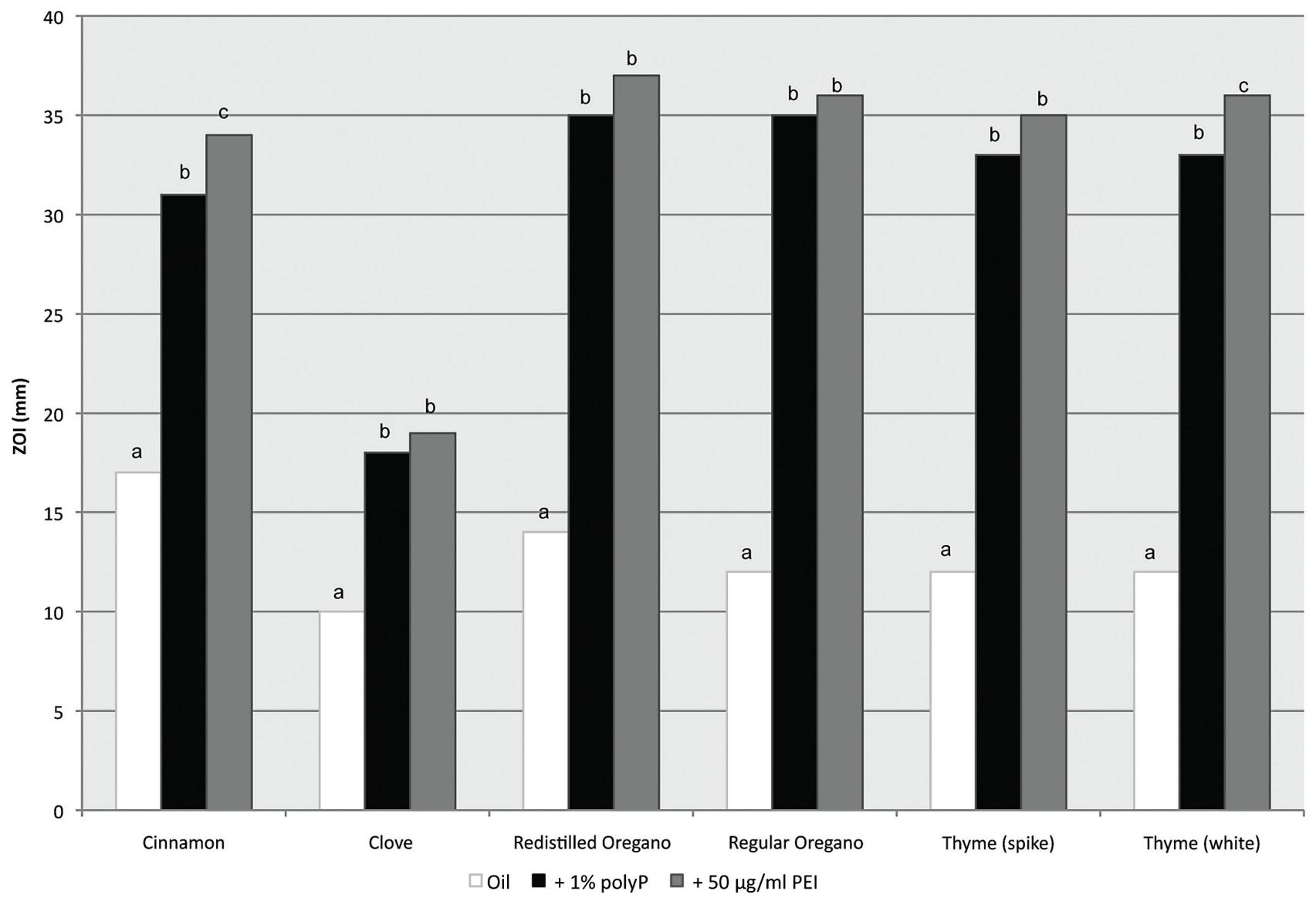

Figure 1. Zones of inhibition $(\mathrm{mm})$ for six essential oils against $L$. monocytogenes F6854, alone and in the presence of polyP (1\%) or PEI $(50 \mu \mathrm{g} / \mathrm{ml})$. For each essential oil, treatments having the same letter are not significantly different $(p<0.05)$. 


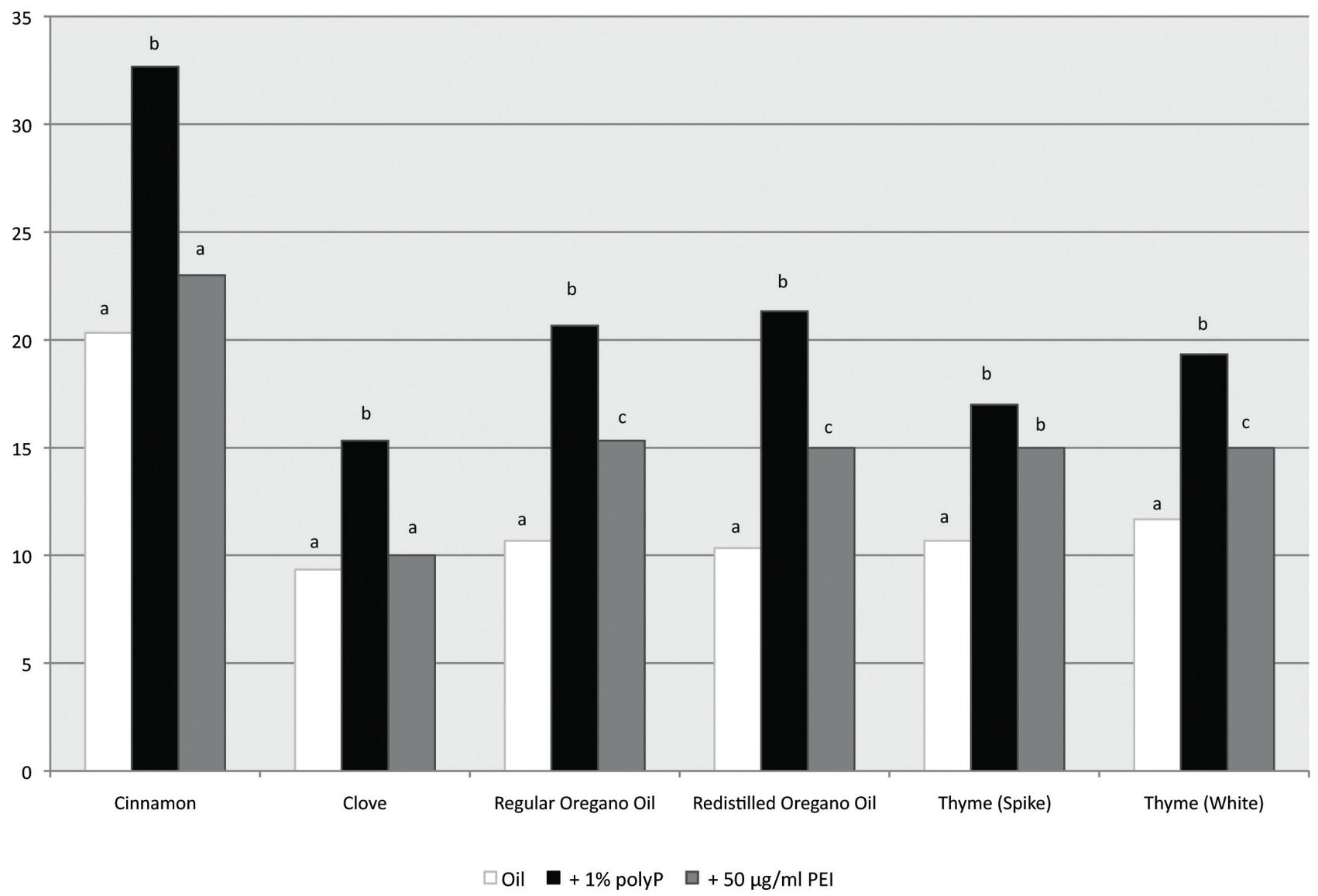

Figure 2. Zones of inhibition ( $\mathrm{mm}$ ) for six essential oils against $P$. aeruginosa ATCC 27853, alone and in the presence of polyP (1\%) or PEI $(50 \mu \mathrm{g} / \mathrm{ml})$. For each essential oil, treatments having the same letter are not significantly different $(p<0.05)$.

resistance to EO activity than E. coli, but also showing increased sensitization to EOs in the presence of both enhancers (Figures 1 and 3; Tables 2 and 3).

Specifically, L. monocytogenes showed a threefold reduction in MIC for both cinnamon and redistilled oregano oils in the presence of polyP, although MICs for E. coli and C. albicans exposed to this sensitizer were reduced by only twofold (cinnamon) and onefold (redistilled oregano) (Table 2). In the presence of PEI, the MIC for redistilled oregano oil against L. monocytogenes was reduced fourfold. For oils tested alone, without enhancers, cinnamon oil was found to be the most effective by broth microdilution, with $C$. albicans being the most intrinsically susceptible organism (Table 2). As noted in Materials and Methods, preliminary experiments revealed that $C$. albicans was fully inhibited by $1 \%$ polyP and by all levels of PEI (as low as $0.39 \mu \mathrm{g} / \mathrm{ml}$ ) tested in this liquid system. Therefore, for $C$. albicans, a non-inhibitory level of $0.25 \%$ polyP was used and MIC/FIC determinations of EO/PEI combinations were not determined (Table 3).

Although our results clearly showed that polyP and PEI were able to enhance the antimicrobial activities of the EOs tested, FIC indices were calculated to formally detect and characterize EO/enhancer synergies. With the exception of L. monocytogenes combined with PEI, all enhancer combinations with cinnamon oil showed synergistic interactions, with FIC indices $\leq 0.5$. The lowest FIC indices (highest levels of synergy) were found for L. monocytogenes treated with combinations of polyP and cinnamon or redistilled oregano oils. Both E. coli and L. monocytogenes were able to grow at levels of polyP as high as $10 \%$ (the highest level tested). FIC values were therefore calculated using this level as input. No antagonistic interactions were found with any of the combinations tested, indicating at least additive interactions between these polyionic enhancers and the EOs tested.

\section{Discussion}

EOs are complex mixtures of natural molecules known to have various biological activities individually as herbivore attractants or repellants; as insect attractants, mating hormones, or antifeedants; or as components of plant defense systems active against bacteria, fungi, and viruses [1,20,24]. Recent consumer trends toward "natural" products, together with the widespread incidence of resistance to traditional antibiotics have driven a strong interest in alternatives to traditional chemical food preservatives, cleaning agents, or antibiotics [2,20]. Although EOs have generated interest as potential food preservatives, 


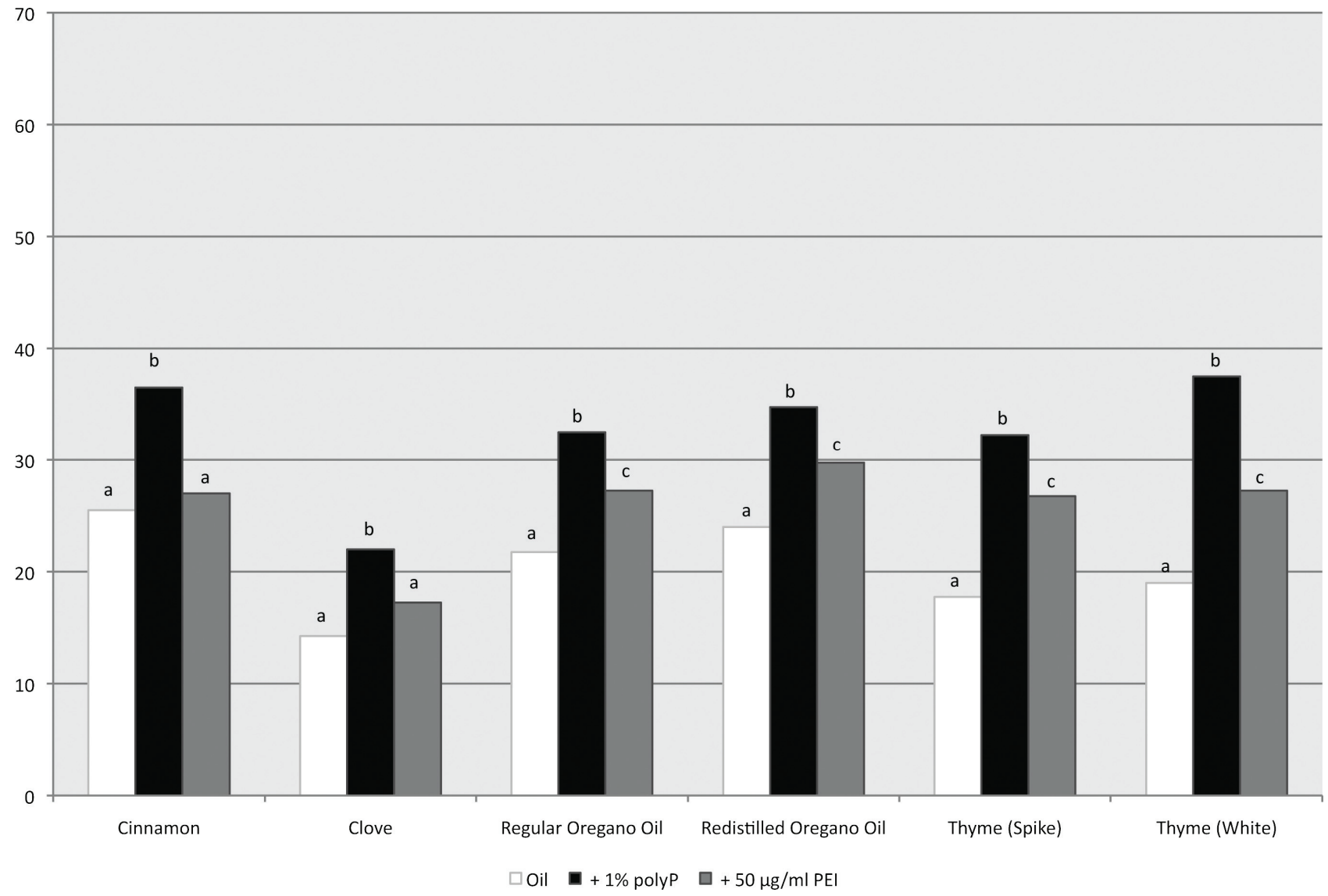

Figure 3. Zones of inhibition ( $\mathrm{mm}$ ) for six essential oils against S. enterica subsp. enterica ser. Minnesota SLH154 ("smooth"/wild-type clinical isolate), alone and in the presence of polyP (1\%) or PEI $(50 \mu \mathrm{g} / \mathrm{ml})$. For each essential oil, treatments having the same letter are not significantly different $(p<0.05)$.

disinfectants, or topical antimicrobials, their practical use can be limited in these roles by their strong aromas, flavors, or other undesirable attributes (as skin irritants, for example). Further, their effective use in complex systems such as foods typically requires their addition at much higher levels (10-100-fold greater) than is required for obtaining the same antimicrobial effects in model media systems [2]. Our study provides an initial in vitro assessment of these two polyionic compounds as enhancers of EO activity against gram-negative bacteria, grampositive bacteria, and fungi. Although we have not yet studied the practical application of these basic enhancement phenomena to specific food, environmental, or clinical systems, we believe that methods such as ours for potentiating or enhancing the existing antimicrobial effects of EOs may ultimately facilitate use of EOs as realistic alternatives to existing chemical preservatives, disinfectants, or antibiotics. Potentially, such methods could either be used to boost EO efficacy at current usage levels, or enable formulation of effective EO-based antimicrobials at substantially lower EO levels, thereby minimizing the undesirable attributes of such systems.

In this study, we have demonstrated that the polyionic compounds polyP (a polyanion) and PEI (a polycation) can be used as effective modulators of EO antimicrobial activity, not only against gram-negative bacteria (E. coli 0157:H7, $P$. aeruginosa, $S$. Minnesota), but also against other cell types, including gram-positive bacteria ( $L$. monocytogenes, $S$. aureus) and a pathogenic yeast ( $C$. albicans). We have shown that polyP and PEI are able to enhance the activities of all oils tested and that certain combinations, such as cinnamon oil and polyP against $E$. coli, L. monocytogenes, and C. albicans, are measurably synergistic, as determined using FIC analyses. Intriguing new data have also been collected on both the intrinsic susceptibility of an LPS-deficient "deep-rough" mutant of $S$. Minnesota to EOs, as well as the additional enhancing effects of polyP or PEI on the antimicrobial effects of EOs against this strain. Collectively, our results suggest excellent potential for polyP and PEI in the formulation of more effective EO-based treatments for use as alternative antimicrobials.

Both polethylenimine (also spelled "polyethyleneimine" in some publications) and polyP are multifunctional molecules, with a diversity of applications in industry as functional ingredients. PEI is a synthetic, cationic polymer whose positive charge stems from the presence of primary, secondary, and tertiary amino groups $[10,13]$. PEI is available in a variety of 


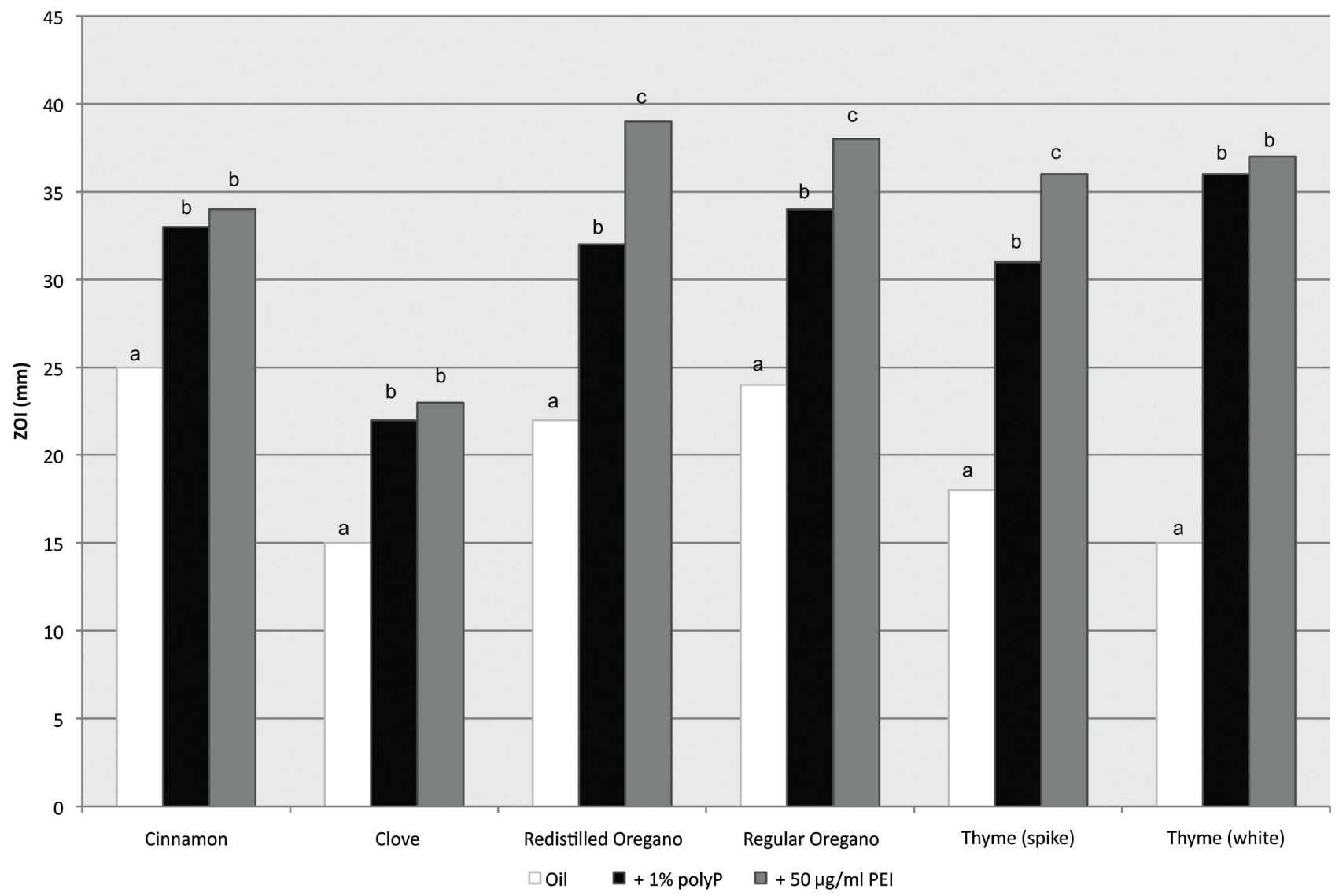

Figure 4. Zones of inhibition (mm) for six essential oils against E. coli 0157:H7 ATCC 35150, alone and in the presence of polyP (1\%) or PEI $(50 \mu \mathrm{g} / \mathrm{ml})$. For each essential oil, treatments having the same letter are not significantly different $(p<0.05)$.

forms, including straight-chain and branched forms and it has been used in applications as varied as a DNA carrier and delivery vector for gene therapy applications, as a flocculant in paper production and waste water treatment and as an ingredient in the manufacture of cosmetic or personal care products, including shampoos [11,25]. The U.S. Code of Federal Regulations also allows PEI as a secondary direct food additive in applications ranging from fixation and immobilization of enzymes for the production of beer, and as an adhesive in food packaging materials.

Polyphosphates are highly anionic condensates of phosphoric acids, and like PEI, are used in a diversity of applications, including multiple food-based applications as acidulants or alkalizers; as a source of dietary phosphorus; as emulsifiers, stabilizers, or dispersants; as buffers, thickeners, or gelling agents; as leavening or anti-caking agents; and, due to their metal chelating action, as color protectants and inhibitors of lipid oxidation or enzymatic browning [15,21,26]. Polyphosphates are routinely used across many food categories including in process cheese, dairy products, meats, poultry, seafood, vegetables, beverages, and pet foods [21]. Non-food applications of polyphosphates include their use in personal care products, and as "eco-friendly" fire retardants used to fight forest fires. In nature, polyP is found in all cell types (bacterial, archaeal and fungal, protozoan, plant and animal) where it acts variously as a buffering agent, an internal reservoir for inorganic phosphate, a substitute for ATP in kinase reactions, an elicitor of natural competence for bacterial transformation, a structural component in the capsular material of Neisseria spp. and in the processing and degradation of mRNA [27].

Previous studies have demonstrated that PEI is an effective permeabilizer of gram-negative bacteria, facilitating the uptake or action of various compounds, including antibiotics, detergents, or biocides $[10,11,13]$. One study also showed similar permeabilizing effects for PEI against a gram-positive bacterium, Mycobacterium vaccae [28]. However, the physiology of Mycobacterium spp. is not typical of other grampositive bacteria, as they possess a lipid bilayer OM that is more akin in structure and barrier function to that of the gramnegative OM [29]. Although not discussed extensively in light of its role as an enhancer of gram-negative OM permeability, PEI is also capable of chelating divalent metals, including $\mathrm{Cu}^{2+}$ and $\mathrm{Fe}^{2+}$, and has been used in this capacity to protect enzymes against metal-catalyzed oxidation [30]. Although the antibioticor biocide-sensitizing properties of PEI have been examined thoroughly for gram-negative bacteria, it was not clear what uptake enhancement activities, if any, PEI might have for 


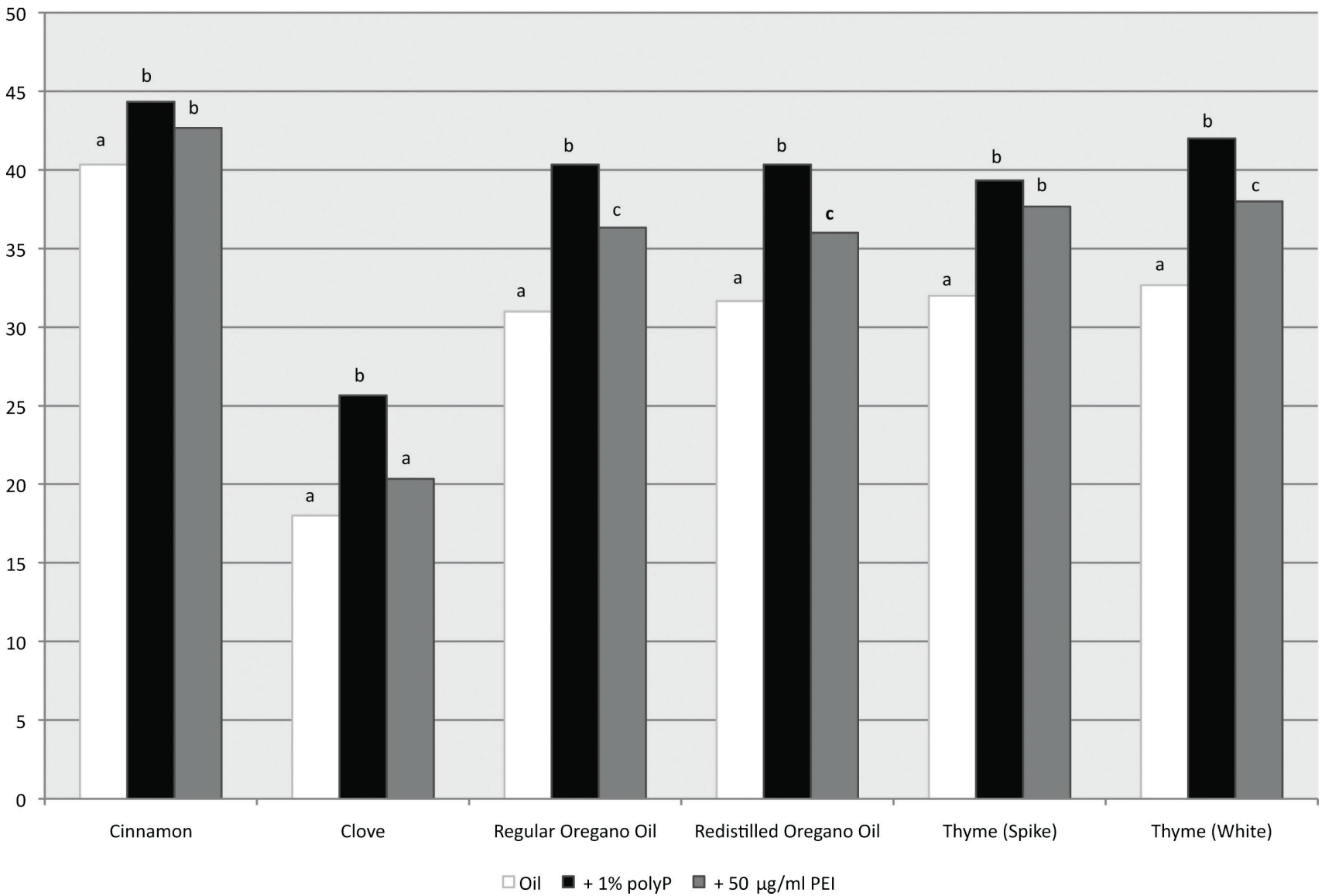

Figure 5. Zones of inhibition ( $\mathrm{mm}$ ) for six essential oils against S. aureus ATCC 29523, alone and in the presence of polyP (1\%) or PEI $(50 \mu \mathrm{g} / \mathrm{ml})$. For each essential oil, treatments having the same letter are not significantly different $(p<0.05)$.

exogenous compounds such as EOs when used against gram-positive bacteria, or yeasts. Likewise, although the OMpermeabilizing effects of polyP are well known [15,16], its potential for use as an enhancer of compounds other than antibiotics and against organisms other than gram-negative bacteria was not clear prior to our study.

The physiological responses of gram-positive bacteria to challenge with polyP alone have been well characterized [31,32]. For Bacillus cereus, effects of lower levels of polyP $(0.05 \%)$ included inhibition of growth, and morphological changes, including filamentation and interference with septum formation [32]. At higher concentrations, polyP caused lysis of vegetative cells and was also sporicidal [32]. With $S$. aureus, $0.1 \%$ polyP caused leakage of intracellular contents and cell lysis [31]. These effects have been largely attributed to the ability of polyP to sequester structurally important divalent cations from gram-positive bacteria, a notion supported by the fact that the inhibitory effects of polyP can be avoided or reversed through the addition of divalent metal cations, such as $\mathrm{Mg}^{2+}$ and $\mathrm{Ca}^{2+}$ [15,31-33]. It is important to note that in this work, we used CAMHB, a medium that is supplemented with both calcium and magnesium at levels of $20-25 \mathrm{mg} / \mathrm{L}$ and $10-12.5 \mathrm{mg} / \mathrm{L}$, respectively (per manufacturer's product data sheet). Therefore, even greater antimicrobial effects of polyP/EO combinations may be possible when these are used in cation-deficient systems. As described in "Results" above, we noted a color change (from a greenish-blue hue, to white or cream) in $P$. aeruginosa lawns grown on plates containing polyP. The same effect was not observed on plates containing PEI. P. aeruginosa is well characterized as producing colored metabolites, including pyocyanin and other phenazine compounds, which are thought to play a role in infection [34]. In addition to growth on specific carbon sources or the presence of certain amino acids or Krebs cycle metabolites, conditions known to stimulate production of pyocyanin and other phenazines include phosphate deficiency or the presence of magnesium ions [34]. Therefore, it is reasonable to expect that treatment of $P$. aeruginosa with high levels of cation-chelating polyphosphate could modulate or suppress the production of these colored phenazine metabolites. Given the assumed role of these metabolites as infection-associated virulence factors, treatment of $P$. aeruginosa with polyP could have additional benefits in clinical applications beyond simply increasing susceptibility to EOs and other hydrophobic antimicrobials. 


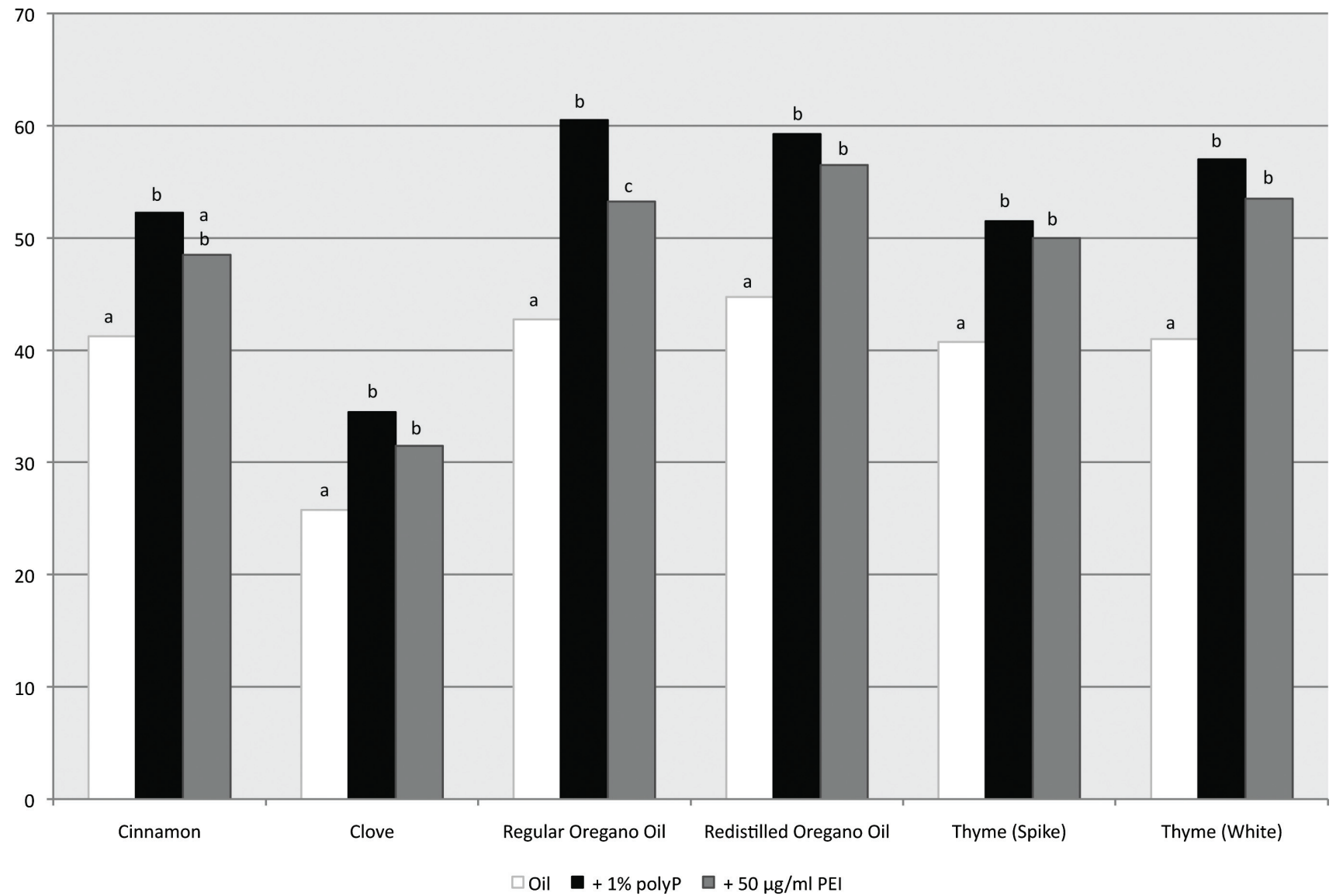

Figure 6. Zones of inhibition $(\mathrm{mm})$ for six essential oils against S. enterica subsp. enterica ser. Minnesota R613 ('ddeep rough", Re chemotype), alone and in the presence of polyP (1\%) or PEI $(50 \mu \mathrm{g} / \mathrm{ml})$. For each essential oil, treatments having the same letter are not significantly different $(p<0.05)$.

Previous studies have shown that gram-positive bacteria are typically more sensitive to EOs than are gram-negative bacteria, presumably due to the presence of the OM [2]. It is known that an intact gram-negative $\mathrm{OM}$ represents an effective barrier against hydrophobic antimicrobials and that the chelating activities of polyP and PEI weaken the OM through removal of the divalent cations that link adjacent molecules of LPS via

Table 1. Summary of increases in zone size for test organisms treated with $1 \%$ polyP or $50 \mu \mathrm{g} / \mathrm{ml} \mathrm{PEI}$.

\begin{tabular}{llc}
\hline Test organism & $\begin{array}{r}\text { Increase in zone size, relative to control } \\
\text { (range of increase, in } \mathbf{~ m m} \text { ) } \\
\text { 1\% polyP } \mathbf{5 0} \boldsymbol{\mu g} / \mathbf{m l ~ P E I}\end{array}$ \\
\hline P. aeruginosa & $6-13$ & $1-5$ \\
E. coli O157:H7 & $7-21$ & $8-22$ \\
L. monocytogenes & $8-23$ & $9-24$ \\
S. aureus & $4-9$ & $2-6$ \\
S. Minnesota (wild type) & $8-19$ & $1-9$ \\
S. Minnesota (deep rough) & $9-18$ & $6-13$ \\
\hline
\end{tabular}

For each test organism, minimum and maximum increases in zone size $(\mathrm{mm})$ are listed as a function of the enhancer used. electrostatic bridging $[9,13]$. In light of both the known intrinsic resistance of gram-negatives to EOs and our results that polyP and PEI can enhance EO activity against these bacteria, we hypothesized that a gram-negative bacterium without an intact OM should have increased susceptibility to EOs alone. To probe this further, we examined the activities of EOs against a "deeprough" (Re chemotype) mutant of $S$. Minnesota, both with and without the addition of polyP or PEI. Re chemotype mutants, such as the $S$. Minnesota strain used in our work, possess a severely truncated LPS containing only the 3-deoxy-D-mannooctulosonate residues of the core oligosaccharide attached to lipid A. These strains are unable to incorporate as many proteins in the $\mathrm{OM}$ as wild-type cells. These "voids" are subsequently filled with phospholipid patches, which act as channels for diffusion of hydrophobic compounds, leading to a more gram-positive-like susceptibility phenotype for deeprough mutants treated with hydrophobic antimicrobials $[9,16]$. Although the LPS of Re chemotype mutants is truncated, divalent cations still play a role in linking the remaining adjacent LPS molecules not displaced by phospholipid patches. The fact that treatment of the rough mutant with polyP or PEI led to increased susceptibility of this strain to EOs reinforces 


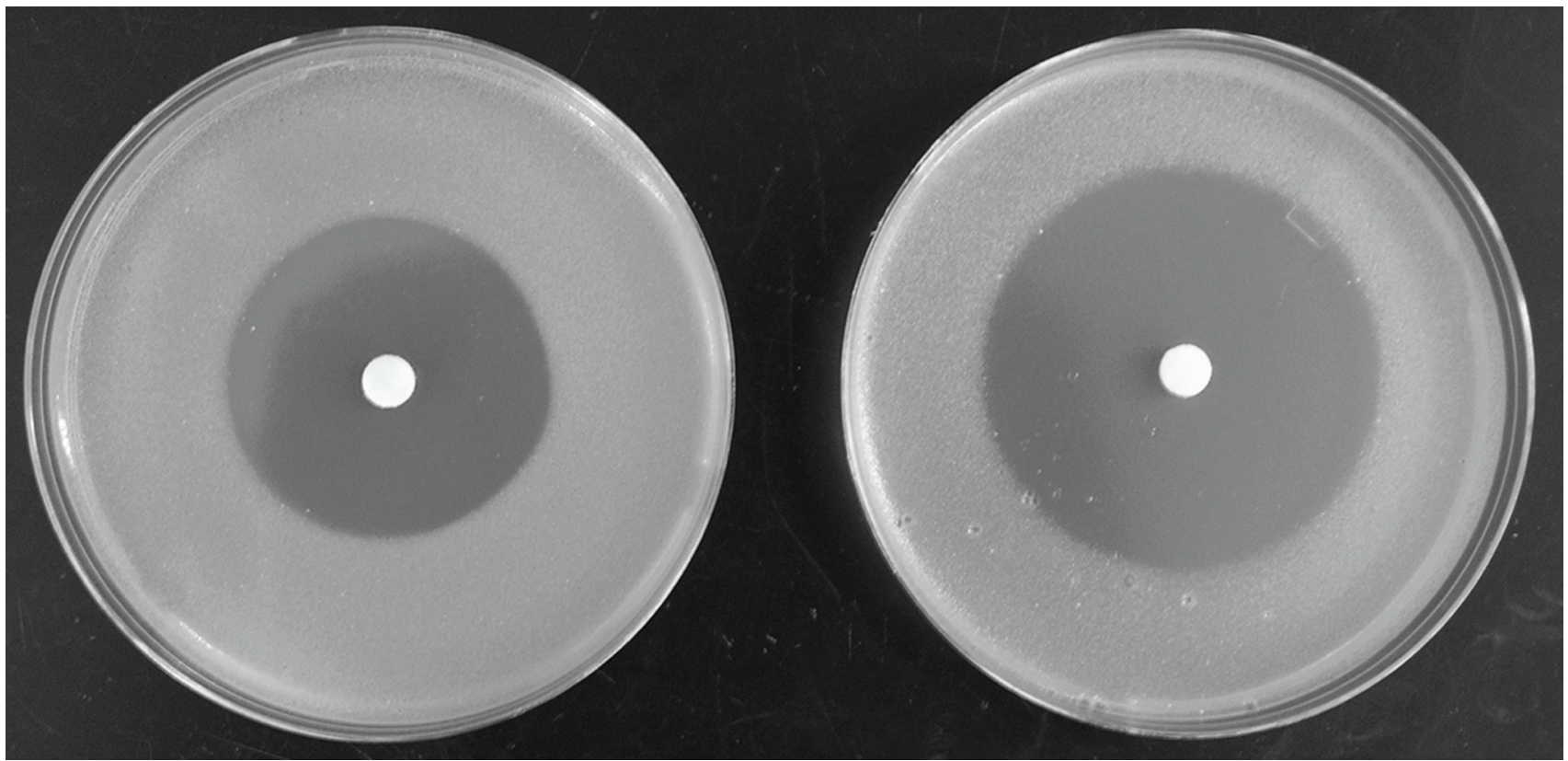

Figure 7. Zone of inhibition obtained for cinnamon oil against C. albicans ATCC 90028 treated with a subinhibitory level (5 $\mu \mathrm{g} / \mathrm{ml})$ PEI. ZOI for cinnamon-only control (plate on left) was $40 \mathrm{~mm}$. Treatment with $5 \mu \mathrm{g} / \mathrm{ml}$ PEI (plate on right) yielded a ZOI of $52 \mathrm{~mm}$ (12 mm increase in zone size). These data show that susceptibility of $C$. albicans to EOs can be effectively enhanced using 10-fold less PEI than found to be effective as an enhancer for bacteria.

the notion that chelation of structurally important metal cations is the chief mode of action of these polyion enhancers against gram-negative cells.

Work with EDTA and 1,10-o-phenanthroline has shown that these compounds inhibit yeast growth by chelating the zinc

Table 2. Fractional inhibitory concentration (FIC) indices and interpretations (synergy or indifference) for E. coli 0157:H7 ATCC 35150, L. monocytogenes F6854, and C. albicans ATCC 90028 treated with cinnamon oil or redistilled oregano oil, with or without $1 \%$ polyP.

\begin{tabular}{|c|c|c|c|}
\hline & \multicolumn{2}{|c|}{$\begin{array}{c}\text { Minimum inhibitory } \\
\text { concentration (\% v/v oil) }\end{array}$} & \multirow{2}{*}{$\begin{array}{c}\text { FIC index } \\
\left(\text { Interpretation }{ }^{\mathrm{b}}\right)\end{array}$} \\
\hline & Control (EO alone) & polyP $P^{a}$ & \\
\hline \multicolumn{4}{|l|}{ E. coli O157:H7 } \\
\hline Cinnamon oil & 0.0313 & 0.0078 & $0.251(\mathrm{~S})$ \\
\hline $\begin{array}{l}\text { Redistilled } \\
\text { oregano oil }\end{array}$ & 0.0625 & 0.0313 & $0.503(I)$ \\
\hline \multicolumn{4}{|l|}{ L. monocytogenes } \\
\hline Cinnamon oil & 0.0625 & 0.0078 & $0.126(S)$ \\
\hline $\begin{array}{l}\text { Redistilled } \\
\quad \text { oregano oil }\end{array}$ & 0.25 & 0.0313 & $0.128(S)$ \\
\hline \multicolumn{4}{|l|}{ C. albicans } \\
\hline Cinnamon oil & 0.0156 & 0.0039 & $0.253(\mathrm{~S})$ \\
\hline $\begin{array}{l}\text { Redistilled } \\
\text { oregano oil }\end{array}$ & 0.0625 & 0.0313 & $0.525(I)$ \\
\hline
\end{tabular}

polyP alone exhibited the following MICs: $>10 \%$ (E. coli and L. monocytogenes) or $1.25 \%$ (C. albicans).

${ }^{\mathrm{a}} 1 \%$ polyP used for bacteria, $0.25 \%$ polyP used for C. albicans;

${ }^{\mathrm{b}} \mathrm{S}$, synergy; I, indifference. needed for normal cell wall biogenesis [35]. It is reasonable to expect that polyP can also readily chelate zinc. In keeping with this, the polyP preparation used here (BEKAPLUS FS) is described in product literature as being fungistatic, a claim that is also supported by our results for $C$. albicans. Both polyP

Table 3. Fractional inhibitory concentration (FIC) indices and interpretations (synergy or indifference) for E. coli $0157: \mathrm{H} 7$ ATCC 35150 and L. monocytogenes F6854 treated with cinnamon oil or redistilled oregano oil, with or without $50 \mu \mathrm{g} / \mathrm{ml} \mathrm{PEl}$. PEI alone exhibited the following MICs: $100 \mu \mathrm{g} / \mathrm{ml}$ (E. coli and L. monocytogenes) or $<0.39 \mu \mathrm{g} / \mathrm{ml}$ (C. albicans).

\begin{tabular}{|c|c|c|c|}
\hline & \multicolumn{2}{|c|}{$\begin{array}{c}\text { Minimum inhibitory } \\
\text { concentration (\% v/v oil) }\end{array}$} & \multirow[b]{2}{*}{$\begin{array}{c}\text { FIC index } \\
\left(\text { (Interpretation }^{b}\right)\end{array}$} \\
\hline & $\begin{array}{l}\text { Control } \\
\text { (EO alone) }\end{array}$ & $+50 \mu \mathrm{g} / \mathrm{ml}$ PEI & \\
\hline \multicolumn{4}{|l|}{ E. coli $0157: \mathrm{H7}$} \\
\hline Cinnamon oil & 0.0313 & 0.0039 & 0.452 (S) \\
\hline $\begin{array}{l}\text { Redistilled } \\
\quad \text { oregano Oil }\end{array}$ & 0.0625 & 0.0156 & $1.810(\mathrm{I})$ \\
\hline \multicolumn{4}{|l|}{ L. monocytogenes } \\
\hline Cinnamon oil & 0.0625 & 0.0078 & 0.842 (I) \\
\hline $\begin{array}{l}\text { Redistilled } \\
\quad \text { oregano oil }\end{array}$ & 0.25 & 0.0156 & $1.622(\mathrm{I})$ \\
\hline \multicolumn{4}{|l|}{ C. albicans } \\
\hline Cinnamon oil & 0.0156 & $N / D^{a}$ & - \\
\hline $\begin{array}{l}\text { Redistilled } \\
\quad \text { oregano oil }\end{array}$ & 0.0625 & $N / D^{a}$ & - \\
\hline
\end{tabular}

${ }^{a}$ Not determined, as PEI alone was inhibitory to C. albicans at $50 \mu \mathrm{g} / \mathrm{ml}$; ${ }^{\mathrm{b}} \mathrm{S}$, synergy; I, indifference. 
and clove EO are also known to chelate iron $[33,36]$. Because iron is an essential nutrient for microbial growth [37], sequestration of iron by polyP/EO combinations may represent a secondary means for these mixtures to inhibit microbial growth, beyond physical permeabilization.

Among the physiological effects that Burt [2] found for carvacrol was that this component of thyme and oregano EOs inhibits the formation of flagellin. Cells of E. coli 0157:H7 exposed to $1 \mathrm{mM}$ carvacrol were aflagellate and nonmotile [2]. Because bacterial flagella mediate attachment to both host cells and inanimate surfaces, carvacrol may therefore interfere with attachment of bacteria to host or environmental surfaces [38]. Polyphosphates are also thought to promote detachment of pre-biofilm salivary proteins to tooth enamel or bacteria to food surfaces $[39,40]$. Combinations of polyP and EOs may therefore have promise as inhibitors of bacterial attachment through a combination of overt physiological effects on cells and physical effects on the surfaces to which they are attached.

In additional to their direct activities as antimicrobial enhancers, functional ingredients such as polyP and PEI could also exert important effects from a formulation perspective. For antimicrobials to be effective in foods, they must be available in the aqueous phase, which is problematic for hydrophobic compounds such as EOs [5]. The emulsifying properties of polyP may therefore be beneficial in polyP/EO combinations, as polyP could potentially function to promote or stabilize EO emulsions, minimizing the negative effects of phase partitioning on EO availability.

Finally, it is generally recognized that EOs are more effective antimicrobials at acidic $\mathrm{pH}$ values, which may reflect their increased solubility at lower $\mathrm{pH}$ or the presence of certain EO components in higher concentration in their undissociated form $[2,4]$. Ultee et al. [14] suggested that the undissociated form of carvacrol may behave as a mobile proton/cation exchanger, whose action diminishes the $\mathrm{pH}$ gradient across the cell membrane. In our experiments, addition of polyP or PEI did not affect the $\mathrm{pH}$ of the CAMBH medium used. CAMBH containing polyP or PEI at final working concentrations maintained neutral $\mathrm{pH}$ values between 7.1 and 7.3 , close to the manufacturer's specifications of $7.3, \pm 0.1$. Because certain phosphates are routinely used in the food industry as acidulants, it would be interesting to use these to formulate polyP-EO systems having acidic $\mathrm{pH}$ values and to investigate the antimicrobial activities of these low-pH systems vis-à-vis $\mathrm{pH}$ neutral systems. Alternatively, the final $\mathrm{pH}$ of such systems could be adjusted using organic acids, which themselves may have chelating activities [5,6].

In summary, we have shown that both polyP and PEI can be effectively used at subinhibitory levels to enhance the antimicrobial activities of select EOs against gram-negative bacteria (E. coli 0157:H7, S. Minnesota, P. aeruginosa), gram-positive bacteria (L. monocytogenes and $S$. aureus), and a pathogenic yeast (C. albicans). Enhancement for certain polyion/EO combinations was measurably synergistic. Experiments with a "deep-rough" mutant of $S$. Minnesota reinforced the role of the $\mathrm{OM}$ in the intrinsic resistance of gram-negative bacteria to EOs. The fact that polyP and PEI were able to further potentiate the activities of EOs against the rough mutant suggests that polyP and PEI target features still present in the rough mutant, such as magnesium ions bridging adjacent LPS molecules. The unique properties of polyP and PEI as functional ingredients may confer additional benefits to polyion/EO systems by facilitating bacterial detachment, interfering with the production of infection-related virulence factors (i.e. pyocyanin) or promoting emulsification and availability of EOs in the aqueous phase of matrices in which these combinations are applied. This work extends what is known about the antimicrobialsensitizing potential of both polyP and PEI for compounds other than antibiotics or biocides and suggests a potential role for these polyionic enhancers in effective multicomponent antimicrobial mixtures for use in food, environmental, or medical applications. Some combinations, such as polyP and certain EOs also have the added benefit of being fully GRAS, which may ultimately facilitate their use in foods or in food-related applications, such as dips or sprays. Further work should be done to determine the efficacy of such systems in foods, to examine the capacity of EO/polyion combinations to address antimicrobial-resistant clinical strains [10], and to address more basic questions such as how $\mathrm{pH}$ or control of the emulsion may affect the behavior of polyion/EO systems, with the ultimate goal of developing systems having improved antimicrobial activities.

\section{Acknowledgements}

The authors thank Van Beek Natural Science (Orange City, IA) for supplying essential oils and BK Giulini Corporation (Simi Valley, CA) for supplying the polyP used in this study. Funding for this work was provided by USDA National Needs Fellowship Grant No. 2005-02324, Van Beek Natural Science, and the Institute for Physical Research and Technology (IPRT) at Iowa State University.

\section{References}

[1] Bakkali, F., Averbeck, S., Averbeck, D., \& Idaomar, M. (2008). Biological effects of essential oils - A review. Food and Chemical Toxicology, 46, 446-475. http://dx.doi.org/10.1016/j.fct.2007. 09.106.

[2] Burt, S. (2004). Essential oils: Their antibacterial properties and potential applications in foods - A review. International Journal Food of Microbiology, 94, 223-253. http://dx.doi.org/10.1016/j. ijfoodmicro.2004.03.022.

[3] Pourmortazavi, S. M., \& Hajimirsadeghi, S. S. (2007). Supercritical fluid extraction in plant essential and volatile oil analysis. Journal of Chromatography A, 1163, 2-24. http://dx.doi.org/10.1016/j. chroma.2007.06.021.

[4] Vigil, A. L.-M., Palou, E., \& Alzamora, S. M. (2005). Naturally occurring compounds - Plant sources. In P. M. Davidson, J. N. Sofos, \& A. L. Branen (Eds.), Antimicrobials in food (3rd ed., pp. 429-452). Boca Raton, FL: CRC Press. 
[5] Blaszyk, M., \& Holley, R. A. (1998). Interaction of monolaurin, eugenol and sodium citrate on growth of common meat spoilage and pathogenic organisms. International Journal of Food Microbiology, 39, 175-183. http://dx.doi.org/10.1016/S0168-1605 (97)00134-7.

[6] Zhou, F., Zhang, B. J. H., Jian, H., Yang, Z., Li, J., Li, J., et al. (2007). Synergistic effect of thymol and carvacrol combined with chelators and organic acids against Salmonella Typhimurium. Journal of Food Protection, 70, 1704-1709. http://dx.doi.org/ 10.4315/0362-028X-70.7.1704.

[7] Henley, D. V., Lipson, N., Korach, K. S., \& Bloch, C. A. (2007). Prepuberal gynecomastia linked to lavender and tea tree oils New England Journal of Medicine, 356, 479-485. http://dx.doi. org/10.1056/NEJMoa064725.

[8] Rutherford, T., Nixon, R., Tam, M., \& Tate, B. (2007). Allergy to tea tree oil: Retrospective review of 41 cases with positive patch tests over 4.5 years. Australasian Journal of Dermatology, 48, 83-87. http://dx.doi.org/10.1111/j.1440-0960.2007.00341.x.

[9] Vaara, M. (1992). Agents that increase the permeability of the outer membrane. Microbiology Reviews, 56, 395-411.

[10] Khalil, H., Chen, T., Riffon, R., Wang, R., \& Wang, Z. (2008). Synergy between polyethylenimine and different families of antibiotics against a resistant clinical isolate of Pseudomonas aeruginosa. Antimicrobial Agents and Chemotherapy, 52, 1635-1641. http://dx.doi.org/10.1128/AAC.01071-07.

[11] Helander, I. M., Alakomi, H.-L., Latva-Kala, K., \& Koski, P. (1997). Polyethylenimine is an effective permeabilizer of gram-negative bacteria. Microbiology, 143, 3193-3199. http://dx.doi.org/ 10.1099/00221287-143-10-3193.

[12] Helander, I. M., Nurmiaho-Lassila, E.-L., Ahvenainen, R., Rhoades, J., \& Roller, S. (2001). Chitosan disrupts the barrier properties of the outer membrane of gram-negative bacteria. International Journal of Food Microbiology, 71, 235-244. http://dx.doi.org/ 10.1016/S0168-1605(01)00609-2.

[13] Alakomi, H.-L., Paananen, A., Suihko, M.-L., Helander, I. M., \& Saarela, M. (2006). Weakening effect of cell permeabilizers on gram-negative bacteria causing biodeterioration. Applied and Environmental Microbiology, 72, 4695-4703. http://dx.doi.org/ 10.1128/AEM.00142-06.

[14] Ultee, A., Bernnik, M. H. J., \& Moezelaar, R. (2002). The phenolic hydroxyl group of carvacrol is essential for action against the food-borne pathogen Bacillus cereus. Applied and Environmental Microbiology, 68, 1561-1568. http://dx.doi.org/10.1128/AEM. 68.4.1561-1568.2002.

[15] Vaara, M., \& Jaakkola, J. (1989). Sodium Hexametaphosphate sensitizes Pseudomonas aeruginosa, several other species of Pseudomonas, and Escherichia coli to hydrophobic drugs. Antimicrobial Agents and Chemotherapy, 33, 1741-1747. http://dx. doi.org/10.1128/AAC.33.10.1741.

[16] Vaara, M. (1993). Antibiotic-supersusceptible mutants of Escherichia coli and Salmonella Typhimurium. Antimicrobial Agents and Chemotherapy, 37, 2255-2260. http://dx.doi.org/10.1128/ AAC.37.11.2255.

[17] National Committee for Clinical Laboratory Standards. (2002a) Methods for dilution antimicrobial susceptibility tests for bacteria that grow aerobically. Approved standard M7-A7. Wayne, PA: Author.

[18] National Committee for Clinical Laboratory Standards. (2002c). Reference method for broth dilution antifungal susceptibility testing of yeasts. Approved standard M27-A2. Wayne, PA: Author.

[19] National Committee for Clinical Laboratory Standards. (2002b). Performance standards for antimicrobial disk susceptibility tests. Approved standard M2-A9. Wayne, PA: Author.

[20] Brehm-Stecher, B. F., \& Johnson, E. A. (2003). Sensitization of Staphylococcus aureus and Escherichia coli to antibiotics by the sesquiterpenoids nerolidol, farnesol, bisabolol and apritone. Antimicrobial Agents and Chemotherapy, 47, 3357-3360. http:// dx.doi.org/10.1128/AAC.47.10.3357-3360.2003.

[21] Lampila, L. E., \& Godber, J. P. (2001). Food phosphates. In A. L. Branen, P. M. Davidson, S. Salminen and J. H. Thorngate (Eds.), Food additives (2nd ed., pp. 869-963). New York: Marcel Dekker.

[22] Branen, J. K., \& Davidson, P. M. (2004). Enhancement of nisin, lysozyme, and monolaurin antimicrobial activities by ethylenediaminetetraacetic acid and lactoferrin. International Journal of Food Microbiology, 90, 63-74. http://dx.doi.org/10.1016/S01681605(03)00172-7.

[23] Pankey, G. A., \& Ashcraft, D. S. (2005). In vitro synergy of ciprofloxacin and gatifloxacin against ciprofloxacin-resistant Pseudomonas aeruginosa. Antimicrobial Agents and Chemotherapy, 49, 2959-2964. http://dx.doi.org/10.1128/AAC.49.7.2959-2964. 2005.

[24] Pichersky, E., \& Gershenzon, J. (2002). The formation and function of plant volatiles: Perfumes for pollinator attraction and defense. Current Opinion in Plant Biology, 5, 237-243. http://dx.doi.org/10.1016/S1369-5266(02)00251-0.

[25] Godbey, W. T., Wu, K. K., \& Mikos, A. G. (1999). Poly(ethyleneimine) and its role in gene delivery. Journal of Control Release, 60 , 149-160. http://dx.doi.org/10.1016/S0168-3659(99)00090-5.

[26] Davidson, P. M. (1997). Chemical preservatives and natural antimicrobial compounds. In M. P. Doyle, L. R. Beuchat, \& T. J. Montville (Eds.), Food microbiology: Fundamentals and frontiers (pp. 593-627). Washington, DC: ASM Press.

[27] Kornberg, A., Rao, N. N., \& Ault-Riché, D. (1999). Inorganic polyphosphate: A molecule of many functions. Annual Review of Biochemistry, 68, 89-125. http://dx.doi.org/10.1146/annurev. biochem.68.1.89.

[28] Korycka-Machała, M., Ziółkowski, A., Rumijowska-Galewicz, A., Lisowska, K., \& Sedlaczek, L. (2001). Polycations increase the permeability of Mycobacterium vaccae cell envelopes to hydrophobic compounds. Microbiology, 147, 2769-2781. http://dx. doi.org/10.1099/00221287-147-10-2769.

[29] Hoffman, C., Leis, A., Niederweis, M., Plitzko, J. M., \& Engelhardt, H. (2008). Disclosure of the mycobacteral outer membrane: Cryo-electron tomography and vitreous sections reveal the lipid bilayer structure. Proceedings of the National Academy of Sciences of the United States of America, 105, 3963-3967. http:// dx.doi.org/10.1073/pnas.0709530105.

[30] Breccia, J. D., Andersson, M. M., \& Hatti-Kaul, R. (2002). The role of poly(ethyleneimine) in stabilization against metal-catalyzed oxidation of proteins: A case study with lactate dehydrogenase. Biochimica et Biophysica Acta, 1570, 165-173. http://dx.doi.org/ 10.1016/S0304-4165(02)00193-9.

[31] Lee, R. M., Hartman, P. A., Stahr, H. M., Olson, D. G., \& Williams, F. D. (1994). Antibacterial mechanism of long-chain polyphosphates in Staphylococcus aureus. Journal of Food Protection, 57, 289-294. http://dx.doi.org/10.4315/0362-028X-57.4.289.

[32] Maier, S. K., Scherer, S., \& Loessner, M. J. (1999). Long-chain polyphosphate causes cell lysis and inhibits Bacillus cereus septum formation, which is dependent on divalent cations. Applied and Environmental Microbiology, 65, 3942-3949.

[33] Post, F. J., Krishnamurty, G. B., \& Flanagan, M. D. (1963). Influence of sodium hexametaphosphate on selected bacteria. Applied Microbiology, 11, 430-435.

[34] Mavrodi, D. V., Blankenfeldt, W., \& Tomashow, L. S. (2006). Phenazine compounds in fluorescent Pseudomonas spp. Biosynthesis and regulation. Annual Review of Phytopathology, 44, 417-445. http://dx.doi.org/10.1146/annurev.phyto.44.013106. 145710.

[35] Brul, S., \& Coote, P. (1999). Preservative agents in foods: Mode of action and microbial resistance mechanisms. International 
Journal of Food Microbiology, 50, 1-17. http://dx.doi.org/ 10.1016/S0168-1605(99)00072-0.

[36] Jirovetz, L., Buchbauer, G., Stoilova, I., Stoyanova, A., Krastanov, A., \& Schmidt, E. (2006). Chemical composition and antioxidant properties of clove leaf essential oil. Journal of Agricultural and Food Chemistry, 54, 6303-6307. http://dx.doi.org/10.1021/ jf060608c.

[37] Boland, J. S., Davidson, P. M., \& Weiss, J. (2003). Enhanced inhibition of Escherichia coli 0157:H7 by lysozyme and chelators. Journal of Food Protection, 66, 1783-1789. http://dx.doi. org/10.4315/0362-028X-66.10.1783.

[38] Burt, S. A., van der Zee, R., Koets, A. P., de Graaff, A. M., van Knapen, F., Gaastra, W., Haagsman, H. P., \& Veldhuizen, E. J. A. (2007). Carvacrol induces heat shock protein 60 and inhibits synthesis of flagellin in Escherichia coli 0157:H7. Applied and Environmental Microbiology, 73, 4484-4490. http://dx.doi.org/ 10.1128/AEM.00340-07.

[39] Jin, Y., \& Yip, H.-K. (2002). Supragingival calculus: Formation and control. Critical Reviews in Oral Biology and Medicine, 13, 426-441. http://dx.doi.org/10.1177/154411130201300506.

[40] Sampathkumar, B., Khachatourians, G. G., \& Korber, D. R. (2003). High pH during trisodium phosphate treatment causes membrane damage and destruction of Salmonella enterica Serovar Enteritidis. Applied and Environmental Microbiology, 69, 122-129. http:// dx.doi.org/10.1128/AEM.69.1.122-129.2003.

\section{Competing Interests}

The authors declare no competing interests.

\section{PUBLISHING NOTES}

(C) 2017 Wright and Brehm-Stecher. This work has been published open access under Creative Commons Attribution License CC BY 4.0, which permits unrestricted use, distribution, and reproduction in any medium, provided the original work is properly cited. Conditions, terms of use, and publishing policy can be found at www.scienceopen.com.

Please note that this article may not have been peer reviewed yet and is under continuous post-publication peer review. For the current reviewing status please click here or scan the QR code on the right.

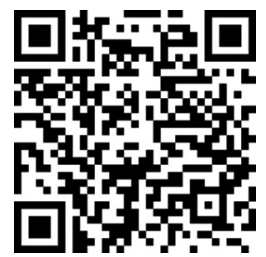

\section{ScienceOPEN.com}

